\title{
The span of apprehension: Form identification as a function of amount of information displayed
}

\author{
JOSEPH S. LAPPIN ${ }^{2}$ VANDERBILT UNIVERSITY \\ AND STEPHEN H. ELLIS, CARNEGIE-MELLON UNIVERSITY
}

Observers were asked to identify each member of a brief display of geometric forms. The information content of the displays was manipulated by varying the number of forms displayed and the number of relevant dimensions of each form. The main findings were: (a) Performance was approximately invariant with the number of forms displayed and depended to a minor degree upon the relevant information in each form. (b) Serial-position curves were obtained that had a strong primacy effect. (c) The number of correct identifications per trial was approximately normally distributed, with greater variance than if the forms were independently identified. These findings are discussed in relation to both "coding rate" and "memory capacity" models of immediate visual memory. Neither model accounts for the data. Undetermined organizational factors are suggested to play a role in immediate visual memory. This task appears to depend upon form identification processes different from those indicated by RT measures.

If a complex display is presented to an observer for a brief time, he will subsequently be able to identify only a limited portion of the information that was presented to him. In the past, it was said that the human observer had a limited "span of apprehension." An experiment to demonstrate this phenomenon might consist of tachistoscopically presenting a set of forms-e.g., digits, letters, geometric shapes-to a $S$ and requesting him to identify as many as possible. It has been found that $S s$ are able to identify correctly an average of between four and seven items per exposure (see Woodworth \& Schlosberg, 1954). At one time, this span of apprehension for sensory input was considered to be one of the fundamental limiting factors in human performance.

Although the theoretical concept of a "span of apprehension" has lost its appeal in favor of more complicated information processing systems (e.g., Sperling, 1960), the operational paradigm to which it was applied retains much of its original utility. In this paper, the "span of apprehension" is employed in its operational, rather than theoretical, sense: Ss are presented with tachistoscopic displays of geometric forms and are asked to identify each form. The "span" of identifiable items is measured for various stimulus materials in order to obtain evidence on the processes by which visual information is coded into verbal responses. The errors in the S's report are presumed to occur because his capacity in this task is limited, and these errors are taken as a measure of this capacity.

It is often suggested or implied that the loss of information that occurs in these tasks is the result of the rapid fading of an "image" from which information is serially transferred to a more permanent memory unit (e.g., Mackworth, 1963; Haber, 1964; Glanzer \& Fleishman, 1967). If this is the case, then the number of forms correctly identifiable in a briefly exposed display should be an increasing monotonic function of the speed with which the items in the image may be coded into a more stable representation. Accordingly, this measure should converge upon the same processes that have soen indicated by measures of reaction time in Iccent studies of form perception (see Smith, 1968). A frequent finding in these reaction-time studies is that the processing time required to identify a form is some increasing function of the number of alternative forms that can appear. Application of this finding to the span of apprehension paradigm yields the prediction that the number of correctly identified forms in a display should decrease as a function of the amount of information in each form.

On the other hand, one might suppose that the span of apprehension is just another form of what is often called "immediate memory span," that the loss of information from brief displays is to be blamed on the same mechanisms that provide error data in other studies of short-term memory. Contrary to the result in RT experiments, it has been found that immediate memory span is relatively independent of the amount of information per item (Pollack, 1953; Miller, 1956). The limit in this case seems to be on the number of responses that can be used to identify the previously presented information.

These alternative models will be designated the "coding rate" and the "memory capacity" models. Predictions from these models diverge with respect to the effect of the information content of the displayed items. In this study, information is added to a brief display in two ways: (a) by increasing the amount of relevant information in each form, and (b) by increasing the number of forms in the display. Comparison of the performance in these conditions should help to reveal the nature of the observer's shortcomings in coding visual input into verbal output.

There is also an additional way in which this coding problem may be examined in the span-of-apprehension task. It is useful to consider the organization of the information obtained from a single presentation. On the majority of trials, the $S$ correctly identifies only some of the forms and erroneously identifies other forms in the display. It seems likely that the identification accuracy for certain combinations of these forms may be positively or negatively correlated, depending upon the structure of the units (or "chunks") in which the displayed information is processed. For example, it might be difficult to perceive both the first and last forms of the series, though easy to perceive either form by itself. One of the purposes of these experiments is to examine the correlation in identification accuracy between items in the display, in order to determine the structure of the information obtained from a single display presentation.

In Experiment 1, the information content of each displayed form is manipulated; in Experiments 2 and 3, the number of displayed forms is also varied; and Experiment 4 measures the speed of oral identifications as a function of the information content of the forms.

\section{EXPERIMENT 1}

\section{Method}

Stimulus displays. Stimulus displays were presented with a Scientific Prototype Model GB three-channel tachistoscope. The pre- and postexposure field contained a small black cross, serving as a fixation point, at a luminance of approximately $15 \mathrm{ft}-\mathrm{L}$. The display presentations were initiated by the $S$. The displays appeared for $125 \mathrm{msec}$ at a luminance of approximately $45 \mathrm{ft}-\mathrm{L}$. The physical characteristics of the displays were intended to be such as to eliminate errors due to an inaccurate discrimination of the value of any single dimension of a form presented by itself.

The stimulus displays consisted of six geometric forms varying on four binary 
Table 1

Experimental Conditions for Each Session and $S$ in Experiment 1

\begin{tabular}{|c|c|c|c|c|c|}
\hline Sessions & Condition & S 1 & S 2 & S 3 & S 4 \\
\hline $\begin{array}{l}1-2 \text { (p) } \\
3-4 \\
5-6 \\
7-8 \\
9-10 \\
11-12 \text { (p) } \\
13-14 \\
15-16 \text { (p) } \\
17-18 \\
19-20 \text { (p) } \\
21-22\end{array}$ & $\begin{array}{l}1 \mathrm{dim} . \\
1 \mathrm{dim} . \\
1 \mathrm{dim} . \\
1 \mathrm{dim} . \\
1 \mathrm{dim} . \\
2 \mathrm{dim} . \\
2 \mathrm{dim} . \\
3 \mathrm{dim} . \\
3 \mathrm{dim} . \\
4 \mathrm{dim} . \\
4 \mathrm{dim} .\end{array}$ & $\begin{array}{r}c \\
c \\
a \\
s \\
o \\
c o \\
c o \\
c o a \\
\text { coa } \\
\text { scoa } \\
\text { scoa }\end{array}$ & $\begin{array}{r}\text { s } \\
\text { s } \\
0 \\
c \\
a \\
\text { sa } \\
\text { sa } \\
\text { sao } \\
\text { sao } \\
\text { scoa } \\
\text { scoa }\end{array}$ & $\begin{array}{r}a \\
a \\
s \\
o \\
c \\
c a \\
c a \\
\text { acs } \\
\text { acs } \\
\text { scoa } \\
\text { scoa }\end{array}$ & $\begin{array}{r}o \\
o \\
c \\
a \\
s \\
\text { so } \\
\text { so } \\
\text { soc } \\
\text { soc } \\
\text { scoa } \\
\text { scoa }\end{array}$ \\
\hline
\end{tabular}

p: practice, c: color, s: size, a: shape, o: outline vs. solid dimensions: red or green, square or circle, large or small ( 21 vs $12 \mathrm{~min}$ ), and outlined or solid. The forms were stencilled on white vinyl cards with felt-tipped pens. They appeared at adjacent positions on a circular array, $1 \mathrm{deg}$ in radius, with 12 possible equally spaced positions. The positioning of the items was determined by selectively masking six of the forms of a 12-form display. A set of 16 of these 12 form displays was obtained from a 12 by 16 matrix, in which each of the 12 rows represents a particular display position and contains a random permutation of the integers, 0 to 15 , the number in each cell represents one of the 16 possible forms, and each of the 16 columns represents a separate display. Two such sets of 16 displays were used, each with a different group of Ss. With each 12-form display, eight different mask of the items. The clock-face positions exposed were from 12 to 5,3 to 8,6 to 11 , 9 to 2,1 to 6,4 to 9,7 to 12 , and 10 to 3 . Four equally spaced masks were used equally often in random order in each session and in each block of 16 trials. The combination of masks with displays was different for each of the four blocks of trials in a session, and the two sets of four masks were alternated after each session. Thus, there were, in all, 256 different six-form displays of the 16 alternative positions were used that exposed some six geometric forms. The ordering of displays in each block was random, being determined by shuffling the 16 cards.

These properties suggest that the six forms in each display may be considered as a combination of six independent random variables, and the trials considered mutually independent. It is also assumed that the sensory discriminability was equal for all of the forms, that errors reflect solely the overload of some central processing mechanism-since the forms in the display were equidistant from the preexposure fixation point, their position was random from trial to trial, and the exposure duration was too brief to permit voluntary eye movements, although quite adequate for all the forms to be seen clearly.

Procedure. The Ss were four students at Carnegie-Mellon University who served as paid volunteers. One of the Ss was a female, two were graduate students in psychology, and one was the second author of this study.

Each S served for 22 sessions. Eight of the sessions were devoted to practice, and the data from them were not analyzed. There were 64 experimental trials per session, which were run in four blocks of 16 trials. The main experimental conditions were concerned with the number of relevant dimensions of each form that were to be identified. Table 1

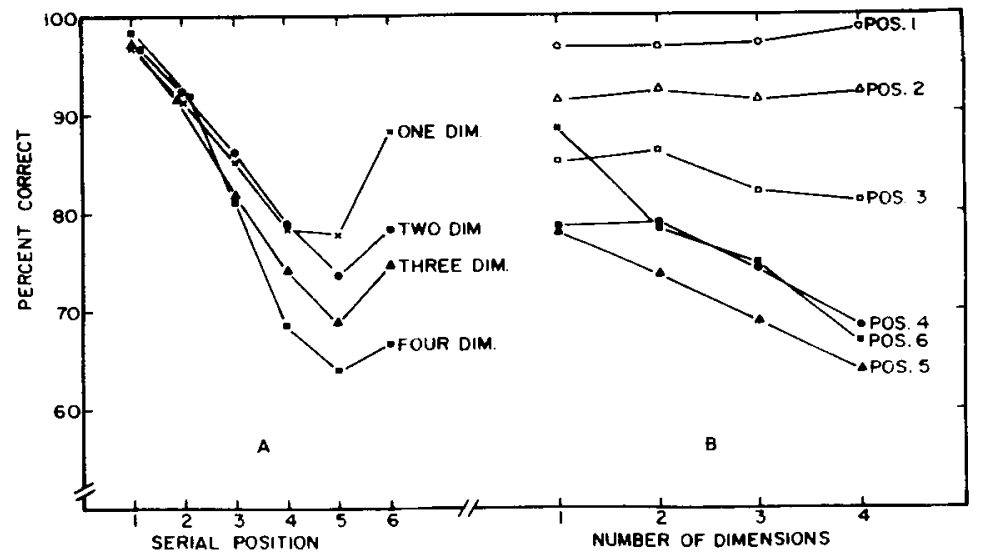

summarizes this aspect of the experimental design.

The six forms were each verbally identified with a single number. The numbers used for each condition were as follows: one dimension, 0 and 1 ; two dimensions, 0 to 3 ; three dimensions, 0 to 7; four dimensions, 0 to 15 . The assignment of a number to each form was such that if the number were written in binary form, each binary digit would represent one of the relevant dimensions. The Ss were informed of this scheme. They were also provided with a card showing each of the 16 forms and the number assigned to it. Prior to the four-dimension condition, the Ss practiced naming the displayed forms and the experiment proper was not begun until this could be done quickly.

On each trial, $S$ made six verbal responses, one for each of the forms in the display. The forms were identified in a clockwise order.

\section{Results}

The identification accuracy of each of the six display positions in each of the four experimental conditions is shown in Fig. 1. The data plotted are the average per cent correct for two dimensions for four Ss. (For each S, just two dimensions were included among the relevant dimensions of every condition.) Figure 1A shows a marked dependence of identification accuracy upon the serial order in which the items are reported. These serial-order curves appear to maintain the same general shape under changes in the amount of relevant information in each form. In Fig. 1B, these same data have been replotted to better portray the effect of information content on the identification of each form. It may be seen that the effect is negligible for the first three items reported, but produces similar decrement for the last three items.

Analysis of variance (serial position by conditions by $\mathrm{Ss}$ ) supports the impressions provided by these figures. Serial positions, conditions, positions by conditions, Ss, and Ss by positions are all significant at $p<.01$. A second analysis (locations by serial position by Ss, using the data from the three- and four-dimension conditions) was done to assess the effects of the location of the six adjacent forms around the 12-position display. There was no significant effect of either the location, $F(7,21)=1.34$, or the interaction of

Fig. 1. Average per cent correct identification of the binary dimensions of six forms in each condition of Experiment 1. 
Table 2

Lower Bounds (See Appendix A) for Information Transmitted (Bits) in Experiment 1

\begin{tabular}{|c|c|c|c|c|c|}
\hline & & \multicolumn{4}{|c|}{ Displayed Information } \\
\hline & & 6 Bits & 12 Bits & 18 Bits & 24 Bits \\
\hline S 1 & $\begin{array}{l}\text { Size } \\
\text { Color } \\
\text { Outline } \\
\text { Shape } \\
\text { Total }\end{array}$ & $\begin{array}{l}2.52 \\
4.11 \\
3.10 \\
2.20 \\
2.98\end{array}$ & $\begin{array}{l}3.24 \\
3.24 \\
6.48\end{array}$ & $\begin{array}{l}3.16 \\
2.79 \\
2.05 \\
8.01\end{array}$ & $\begin{array}{l}2.26 \\
2.49 \\
2.74 \\
2.08 \\
9.57\end{array}$ \\
\hline S 2 & $\begin{array}{l}\text { Size } \\
\text { Color } \\
\text { Outline } \\
\text { Shape } \\
\text { Total }\end{array}$ & $\begin{array}{l}3.66 \\
3.76 \\
3.59 \\
2.59 \\
3.40\end{array}$ & $\begin{array}{l}2.04 \\
5.63\end{array}$ & $\begin{array}{l}3.59 \\
\\
2.84 \\
1.73 \\
8.16\end{array}$ & $\begin{array}{r}3.19 \\
2.67 \\
2.97 \\
1.74 \\
10.57\end{array}$ \\
\hline S 3 & $\begin{array}{l}\text { Size } \\
\text { Color } \\
\text { Outline } \\
\text { Shape } \\
\text { Total }\end{array}$ & $\begin{array}{l}1.50 \\
1.82 \\
1.74 \\
1.05 \\
1.53\end{array}$ & $\begin{array}{l}2.06 \\
0.68 \\
2.74\end{array}$ & $\begin{array}{l}1.36 \\
1.60 \\
0.74 \\
3.70\end{array}$ & $\begin{array}{l}1.01 \\
1.39 \\
0.94 \\
0.82 \\
4.17\end{array}$ \\
\hline$S 4$ & $\begin{array}{l}\text { Size } \\
\text { Color } \\
\text { Outline } \\
\text { Shape } \\
\text { Total }\end{array}$ & $\begin{array}{l}3.90 \\
3.57 \\
3.52 \\
2.92 \\
3.48\end{array}$ & $\begin{array}{l}3.75 \\
3.47 \\
7.22\end{array}$ & $\begin{array}{l}3.09 \\
2.85 \\
2.67 \\
\\
8.60\end{array}$ & $\begin{array}{r}3.40 \\
2.41 \\
2.51 \\
2.15 \\
10.47\end{array}$ \\
\hline & Average & 2.85 & 5.51 & 7.12 & 8.69 \\
\hline
\end{tabular}

Table 3

Average (for $4 \mathrm{Ss}$ ) Percentage Correct Identification of Each of Four Forms as a Function of the Number of Other Correct Identifications on that Trial (Experiment 1)

\begin{tabular}{|c|c|c|c|c|c|}
\hline & \multicolumn{5}{|c|}{ Number of Others Correct } \\
\hline & 1 & 2 & 3 & 4 & 5 \\
\hline $\begin{array}{l}\text { One Dim. } \\
\text { Position } 3 \\
4 \\
5 \\
6 \\
\text { Average }\end{array}$ & & $\begin{array}{l}62.6 \\
56.1 \\
50.3 \\
79.9 \\
62.2\end{array}$ & $\begin{array}{l}74.5 \\
67.1 \\
60.1 \\
79.1 \\
70.2\end{array}$ & $\begin{array}{l}80.8 \\
74.0 \\
71.1 \\
85.3 \\
77.8\end{array}$ & $\begin{array}{l}87.8 \\
85.0 \\
82.9 \\
89.2 \\
86.2\end{array}$ \\
\hline $\begin{array}{l}\text { Two Dim. } \\
\text { Position } 3 \\
4 \\
5 \\
6 \\
\text { Average }\end{array}$ & $\begin{array}{l}27.0 \\
53.4 \\
30.8 \\
31.2 \\
35.7\end{array}$ & $\begin{array}{l}63.6 \\
62.5 \\
53.7 \\
37.5 \\
54.3\end{array}$ & $\begin{array}{l}75.1 \\
60.1 \\
48.9 \\
56.6 \\
60.3\end{array}$ & $\begin{array}{l}80.4 \\
63.7 \\
55.4 \\
63.3 \\
65.7\end{array}$ & $\begin{array}{l}79.8 \\
67.6 \\
67.6 \\
67.6 \\
70.6\end{array}$ \\
\hline $\begin{array}{l}\text { Three Dim. } \\
\text { Position } 3 \\
4^{*} \\
5 \\
6^{*} \\
\text { Average }\end{array}$ & $\begin{array}{l}51.5 \\
34.1 \\
30.6 \\
34.7 \\
37.7\end{array}$ & $\begin{array}{l}52.2 \\
27.4 \\
25.3 \\
24.8 \\
32.4\end{array}$ & $\begin{array}{l}65.4 \\
45.2 \\
33.9 \\
44.2 \\
47.2\end{array}$ & $\begin{array}{l}62.8 \\
53.0 \\
36.6 \\
47.1 \\
49.9\end{array}$ & $\begin{array}{l}72.7 \\
84.7 \\
52.3 \\
56.6 \\
66.6\end{array}$ \\
\hline 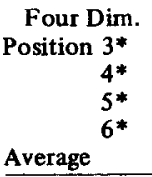 & $\begin{array}{l}48.0 \\
28.1 \\
37.4 \\
37.4 \\
33.5\end{array}$ & $\begin{array}{l}64.5 \\
24.6 \\
24.1 \\
24.1 \\
32.5\end{array}$ & $\begin{array}{l}68.9 \\
31.4 \\
26.9 \\
26.9 \\
37.0\end{array}$ & $\begin{array}{l}61.5 \\
32.8 \\
26.4 \\
26.4 \\
35.7\end{array}$ & $\begin{array}{l}76.4 \\
60.3 \\
60.0 \\
60.0 \\
61.0\end{array}$ \\
\hline
\end{tabular}

* data for only $3 \mathrm{Ss}^{4}$

location and serial position, $F(35,105)=0.63$; thus, the serial position effect is independent of the retinal position of the display. This fact, together with the large primacy effect in the serial-position curves, in dicates that these curves primarily reflect some characteristic of the information processing rather than of the peripheral sensitivity. (Further support for this assertion may be found in the serial-position curves obtained with larger displays in Experiments 2 and 3:) As a test reasonable to assume that the response code for designating the forms has been well 'earned.

A different view of these results is provided by Table 2, which gives the estimated information transmission (see Appendix A for a description of this estimate) for each condition. As may be seen, there is a large increase in the amount of information transmitted when the relevant information of each form is increased.

In order to learn more about the structure of the information obtained from a single display presentation, the dependency between identification of separate items should be examined. The relevant data are provided in Table 3, which gives the average percentage of correct identification of four individual items (those with sufficient errors to analyze) as a function of the number of other forms correctly identified on that trial. ${ }^{3,4}$ If the forms were independently processed, the identification of any particular form would be invariant with respect to the identification accuracy for the other forms. Instead, there was a systematic improvement in performance as more of the other forms were identified. Clearly, the several forms in each display were positively correlated with respect to their chances of being correctly identified. The Ss were rather variable, tending to have either few or many correct identifications.

To get a better look at this aspect of the performance, frequency distributions were calculated for the number of correct responses (correct on all relevant dimensions of each form) made per trial. In Fig. 2, these distributions have been cumulated and are plotted on a normal probability scale. As may be seen, these distributions are approximately normal for all four conditions. Chi-squared tests of fit were made for each $S$ in the four-dimension condition. (Only in this condition are there few occurrences of all six responses being correct, so that the observed mean and variance of the number of correct responses per trial may be taken as estimates of the mean and variance of an underlying theoretical distribution. Moreover, the contribution of error variance from guessing should be least in this condition.) The chi square for the four Ss combined is near the expected vahe under the null hypothesis: $\chi^{2}=10.10$ $(\mathrm{df}=10, \mathrm{p}<.50)$. The fit was significantly deviant at the .20 level for only one of the Ss. Thus, the distribution of correctly identified forms in a single display is approximately normal.

EXPERIMENTS 2 AND 3

The results of Experiment 1 raised some 


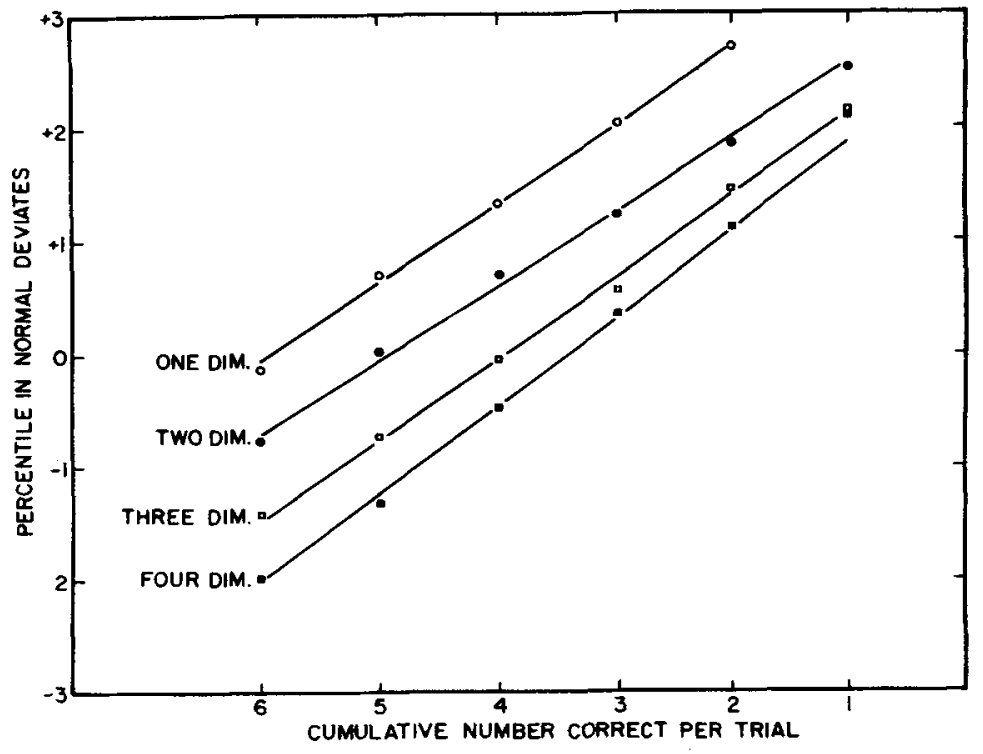

unexpected and interesting possibilities. One of these is that the mechanism by which errors occur in the span-of-apprehension task is dependent upon only a single variable. One way in which this hypothesis could be tested is by varying the number of forms in the display. If the limitation on performance is in fact a function of a single parameter that is a property of the $S$, then the span of apprehension should be invariant with the number of forms in the display. On the other hand, a model that attributes errors to interactions between the displayed forms might predict poorer performance as the number of forms is increased.

Experiments 2 and 3 examine this prediction. Experiment 2 was originally conducted as a pilot experiment prior to Experiment 1 and employed only two Ss. Experiment 3 provides a more extensive replication of Experiment 2.

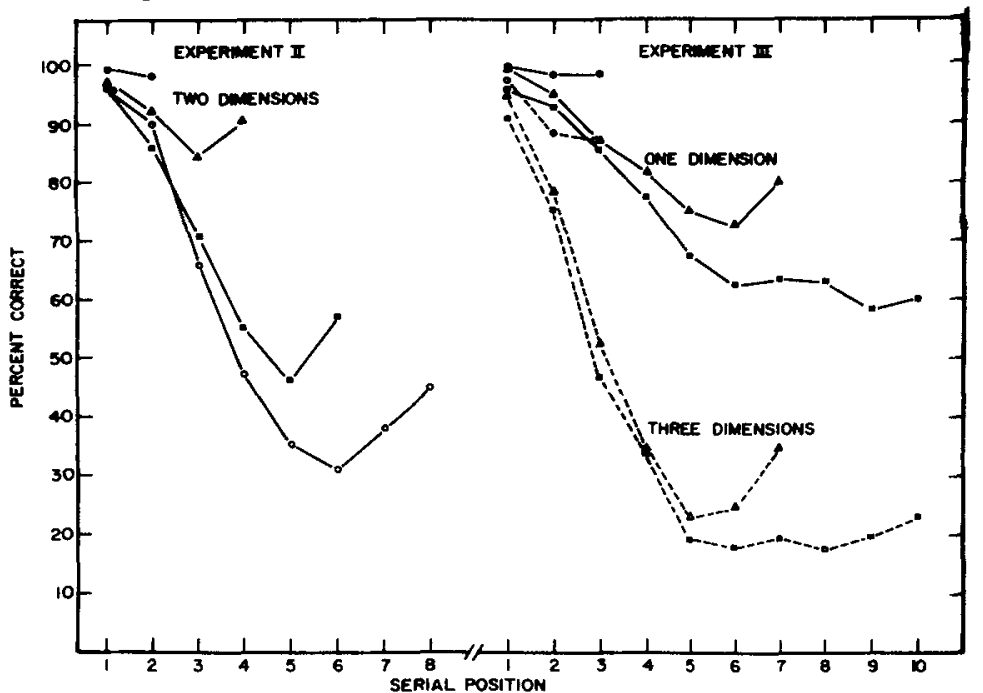

Fig. 2. Cumulated frequency distributions of the number of correct identifications per trial in Experiment 1.

10 forms were presented. One set of 16 12-form displays was used that was different from those used in Experiment 2. The masks that exposed the desired number of forms were positioned so that the first form in the series was located at 1 , 5 , or 9 o'clock. In other respects, the stimulus displays were like those of Experiments 1 and 2.

Procedure. Four Ss were used. Three of the Ss were undergraduates at Carnegie-Mellon University, who served as paid volunteers, and a fourth was the senior author of the study. Two of the Ss were females and two were males.

There were two conditions that differed with respect to the number of relevant dimensions of each form. In the one-dimension condition, all Ss identified the color of each form. In the three-dimension condition, the relevant dimensions were size, color, and whether the figure was outlined or solid.

Each $S$ was run for 10 experimental sessions and 3 practice sessions. The first 5 experimental sessions were devoted to the one-dimension condition for Ss 1 and 2 and to the three-dimension condition for the other two Ss. Two practice sessions were run at the beginning of the experiment and the third was run before beginning the second condition in the last five experimental sessions. Each of the display sizes was run in a separate block of six trials in each session. In the first four sessions, there were six blocks of 16 trials, two for each display size. In the 5 th and 10th sessions, there were three blocks of trials. The ordering of conditions and display sizes was counterbalanced within and between $\mathrm{Ss}$. In the sessions with six blocks of trials, the display sizes in the last three blocks were run in the reversed order from the first three blocks. There were 144 trials for each $\mathrm{S}$ under each condition.

\section{Results}

Typical serial-position curves were again found in these experiments. These are shown in Fig. 3. A correct response in these figures indicates correct identification of all relevant dimensions.

Cumulative normal plots of the distribution of correct responses per trial for each condition are shown in Fig. 4. By this analysis, it may be seen that the

Figure 3. Average per cent correct identification for all dimensions of each form in Experiments 2 and 3. 


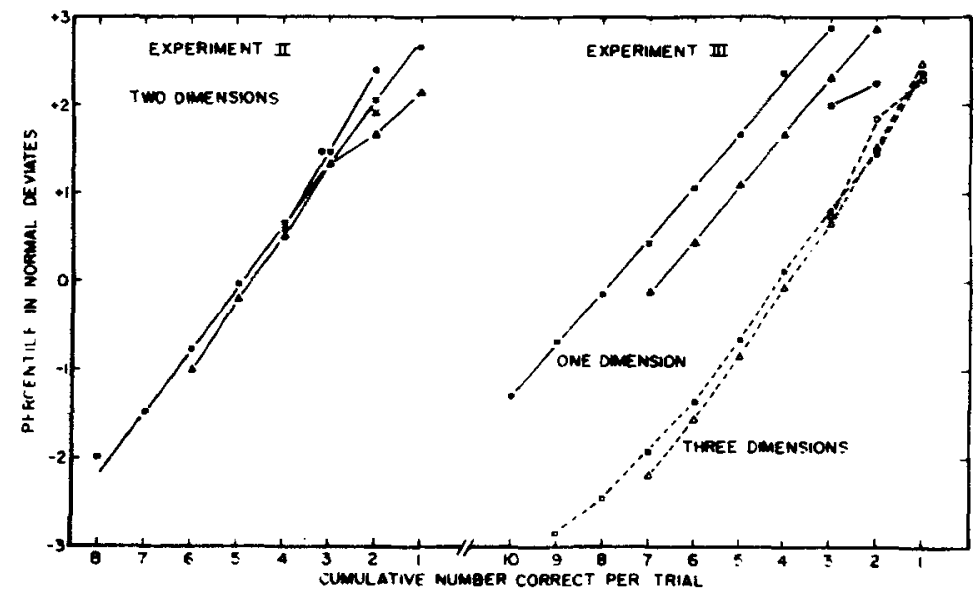

performance is quite comparable with each display size, despite the apparent complexity portrayed by the serial-position curves of Fig. 3.

For those conditions with infrequent cases of either perfect or completely incorrect reports, in which the observed mean and variance may be taken as estimates of underlying theoretical parameters, chi-squared tests were made for the fit of normal densities to the distribution of number of correct responses per trial. As before, the fit is quite close The data involved are from the 8-form condition of Experiment 2, and the 7-and 10-form three-dimension conditions of Experiment 3. The chi squares totaled over Ss for these three conditions, respectively, are: $\chi^{2}=3.98(\mathrm{df}=7, \mathrm{p}<.80), \chi^{2}=13.98$ $(\mathrm{df}=18, \mathrm{p}<.80), \chi^{2}=15.62(\mathrm{df}=21$, $\mathrm{p}<.80$ ).

It is important to consider the effect of display size upon the span of apprehension. This analysis is useful for distinguishing limited capacity models from interference models for the loss of information from complex displays. Figure 4 shows a tendency for superior performance with larger displays, but this superiority diminishes as the number of relevant seem justified. amount of information displayed. dimensions is increased and the likelihood of guessing the additional forms is reduced. Two methods were used to correct for guessing in order to compare performance in conditions with different numbers of responses. Although both of these analyses have shortcomings, several conclusions do

One of the methods employed to correct for guessing was the estimate of information transmission described in Appendix A. The results of this analysis are given in Table 4. It may be seen that performance is roughly comparable for displays in which information is added by increasing the number of forms and is improved by adding to the information in each individual form. The small decline in this performance measure with larger displays may be attributed, in part, to an underestimation of the actual information transmitted, which increases with the

A second correction for guessing was developed by assuming a binomial distribution of correct guesses, where the probability of a correct guess was taken as the reciprocal of the number of alternative identifications. By this model, it was possible to calculate corrected distributions

Table 4

Lower Bounds (See Appendix A) for Information Transmitted (Bits) in Experiments 2 and 3

\begin{tabular}{|c|c|c|c|c|c|c|c|c|}
\hline & & \multicolumn{7}{|c|}{ Number of Forms } \\
\hline & & 2 & 3 & 4 & 6 & 7 & 8 & 10 \\
\hline $\begin{array}{l}\text { One Bit } \\
\text { per Form }\end{array}$ & $\begin{array}{l}\text { S } 1 \\
\text { S } 2 \\
\text { S } 3 \\
\text { S } 4 \\
\text { Average }\end{array}$ & & $\begin{array}{l}2.60 \\
2.88 \\
2.61 \\
2.88 \\
2.74\end{array}$ & & & $\begin{array}{l}2.72 \\
3.18 \\
2.14 \\
4.86 \\
3.22\end{array}$ & & $\begin{array}{l}2.12 \\
2.29 \\
1.52 \\
4.03 \\
2.49\end{array}$ \\
\hline $\begin{array}{l}\text { Two Bits } \\
\text { per Form }\end{array}$ & $\begin{array}{l}\text { S } 1 \\
\text { S } 2 \\
\text { Average }\end{array}$ & $\begin{array}{l}3.88 \\
3.65 \\
3.76\end{array}$ & & $\begin{array}{l}6.30 \\
5.53 \\
5.91\end{array}$ & $\begin{array}{l}5.30 \\
3.91 \\
4.60\end{array}$ & & $\begin{array}{l}5.19 \\
3.44 \\
4.32\end{array}$ & \\
\hline $\begin{array}{l}\text { Three Bits } \\
\text { per Form }\end{array}$ & $\begin{array}{l}\text { S } 1 \\
\text { S } 2 \\
\text { S } 3 \\
\text { S } 4 \\
\text { Average }\end{array}$ & & $\begin{array}{l}6.96 \\
7.42 \\
7.40 \\
6.78 \\
7.14\end{array}$ & & & $\begin{array}{l}5.37 \\
6.15 \\
4.97 \\
6.51 \\
5.75\end{array}$ & & $\begin{array}{l}5.41 \\
4.96 \\
3.82 \\
5.97 \\
5.04\end{array}$ \\
\hline
\end{tabular}

Fig. 4. Cumulated frequency distributions of the number of correct identifications per trial in Experiments 2 and 3.

for the frequency with which $\mathrm{X}$ items were actually "seen" (see Appendix B). It became clear, though, that this model was not valid for the data of these experiments: The computed frequency distributions often had large negative values. The acquisition of information about a form is evidently not an all-or-none process. Nevertheless, the mean of these distributions-the average number of items "seen" per trial-may serve as a useful guideline for comparing different display sizes. These calculations are contained in Table 5. Again, performance is shown to be approximately the same for different display sizes. This analysis also indicates a small decrement in performance for larger display sizes, and it seems likely that this decrement is a real one. The maximum information seems to be acquired from displays of about three or four items.

\section{EXPERIMENT 4}

The findings of the above experiments concerning the effect of adding information to each form in the display (see especially Fig. 1B) have raised some question about the relation of the information-processing demands of this task and those of tasks measuring RT for identifying forms. In the RT experiments, increases in the size of the set from which the forms are sampled have resulted in consistent increases in the time required to identify a form (e.g., Hyman, 1953; Sternberg, 1967). The fact that form uncertainty produced a relatively small decrease in the span of apprehension (see Fig. 1B and Table 5) suggests a different type of constraint on performance in the two tasks.

In Experiment 4, an attempt was made to verify that the speed of form identification for the materials in these studies was comparable to that obtained in other RT experiments. This was accomplished by measuring the time required to identify all of the forms in a display.

\section{Method}

The stimulus displays were those used in Experiment 3. Twelve forms were exposed on each trial, and these were identified in a clockwise order beginning with the 1 o'clock position, Each S was run for 16 trials following at least 2 practice trials. These data were collected, along with the rest of the data of Experiment 3, at the end of the 5th and 10th sessions. These were the last sessions of the 
Table 5

Average Number of Items Correctly "Seen," Assuming a Binomial Distribution of Guesses (See Appendix B), in Experiments 2 and 3

\begin{tabular}{|c|c|c|c|c|c|c|c|c|}
\hline & & \multicolumn{7}{|c|}{ Number of Forms } \\
\hline & & 2 & 3 & 4 & 6 & 7 & 8 & 10 \\
\hline One Dim. & $\begin{array}{l}\text { S } 1 \\
\text { S } 2 \\
\text { S } 3 \\
\text { S } 4 \\
\text { Average }\end{array}$ & & $\begin{array}{l}2.89 \\
2.97 \\
2.89 \\
2.97 \\
2.93\end{array}$ & & & $\begin{array}{l}4.54 \\
4.71 \\
3.85 \\
6.17 \\
4.82\end{array}$ & & $\begin{array}{l}4.51 \\
3.82 \\
3.64 \\
6.08 \\
4.51\end{array}$ \\
\hline Two Dim. & $\begin{array}{l}\text { S } 1 \\
\text { S } 2 \\
\text { Average }\end{array}$ & $\begin{array}{l}1.98 \\
1.95 \\
1.96\end{array}$ & & $\begin{array}{l}3.66 \\
3.40 \\
3.53\end{array}$ & $\begin{array}{l}3.84 \\
3.15 \\
3.50\end{array}$ & & $\begin{array}{l}3.84 \\
2.88 \\
3.31\end{array}$ & \\
\hline Three Dim. & $\begin{array}{l}\text { S } 1 \\
\text { S } 2 \\
\text { S } 3 \\
\text { S } 4 \\
\text { Average }\end{array}$ & & $\begin{array}{l}2.63 \\
2.78 \\
2.73 \\
2.63 \\
2.69\end{array}$ & & & $\begin{array}{l}2.61 \\
2.80 \\
2.82 \\
3.43 \\
2.92\end{array}$ & & $\begin{array}{l}2.59 \\
2.61 \\
2.48 \\
3.20 \\
2.72\end{array}$ \\
\hline
\end{tabular}

span-of-apprehension task under each of the two conditions of form uncertainty (one or three relevant dimensions). The Ss were those of Experiment 3.

The displays were presented in the tachistoscope for a duration that easily exceeded the time required for each $S$ to identify the entire display. The identifications used were numbers identical to those of Experiment 3. A Hunter Clockcounter was activated by the stimulus onset and was stopped when S threw ${ }^{*}$ a lever simultaneously with his last form identification.

\section{Results}

Table 6 contains the mean and standard deviation of the time required for each $S$ to identify 12 forms with one and with three bits of information in each form. It may be seen that the time approximately doubles as the information is increased from one to three bits per form. This increase in RT contrasts sharply with performance in the span-of-apprehension task, which shows an increase in the amount of information transmitted (see Tables 2 and 4) and a relatively small decrement in the number of forms identified (see Fig. 1B and Table 5).

\section{DISCUSSION}

The main issue that this study was designed to clarify was whether the S's 1 imited performance in a span-of-apprehension task is more properly attributed to the rate of access of visual

Table 6

Time (Sec) Required to Identify 12 Forms in Experiment 3

\begin{tabular}{lccrrr} 
& \multicolumn{2}{c}{ One Dim. } & & \multicolumn{2}{c}{ Three Dim. } \\
\cline { 2 - 3 } \cline { 5 - 6 } Ss & Mean & Variance & & Mean & Variance \\
\hline 1 & 3.85 & 0.70 & & 9.62 & 1.37 \\
2 & 4.95 & 0.37 & & 11.56 & 6.30 \\
3 & 5.34 & 0.48 & & 9.33 & 1.75 \\
4 & 3.75 & 0.09 & & 8.54 & 1.52 \\
Average & 4.47 & 0.41 & & 9.76 & 2.74 \\
\hline
\end{tabular}

information ("coding-rate model") or to the storage capacity of some memory system ("memory-capacity model"). However, neither of these simple models adequately accounts for the data.

The coding-rate model. Several authors have suggested that the span of apprehension is limited by the rate at which some serial-encoding process can transfer information from a rapidly fading visual image into a more permanent representation (e.g., Mackworth, 1963; Haber, 1964; Glanzer \& Fleishman, 1967). However, the results of the present experiment are incompatible with this model in at least two ways.

First, the frequency distributions of correct responses per trial do not characterize the serial process implied by the coding-rate model. This serial process may be considered an analog of a "pure birth process," in which some variable length of time elapses between the acquisition of successive items, $E_{n}$ and $E_{n+1}$, and the probability of each additional transition from a state $E_{n}$ to $E_{n+1}$ within a given time interval is a decreasing function of $n$. The frequency distributions of correct responses per trial may then be taken to represent the probabilities, $P_{t}(n)$, that exactly $n$ items are processed within a time interval, $t$, the duration of the visual image. It can be shown that such a process would generate positively skewed distributions in which the variance was correlated with the mean. However, the obtained distributions are symmetric, with a slight tendency for the mean and variance to be inversely related (even though the mean and variance should be positively correlated because of differences in the likelihood of guessing correctly in various conditions).

Second, the span of apprehension depends upon the amount of information in each form to a much less degree than does the speed of overt motor responses-as found in Experiment 4 and in a variety of other RT studies (e.g., Hyman, 1953; Sternberg, 1967). RT measures usually indicate that the amount of information processed per unit time is approximately constant for varying amounts of stimulus information, whereas the amount of information transmitted in the span-of-apprehension task increased with the amount of relevant information per form. The point is that the span of apprehension does not seem to depend upon the same serial selection of labels as indicated by overt RTs.

This discrepancy between the span-of-apprehension and RT measures points up a more general problem in specifying the processes underlying the encoding of visual information and in determining the rate of these processes: There is not an adequate set of convergent independent measures. Although the span of apprehension does not depend clearly upon the rate of information acquisition, the present data raise some question about the frequent assumption that RT provides a measure of this rate. There is some indication in the "serial-position" curves that individual forms are serially processed but apparently this serial process is not itself the primary source of errors. These data do, however, seem compatible with Neisser's (1963) measures of perceptual speed.

Hyman and Kaufman (1966) have obtained effects of displayed information upon form identification that are more in accord with the findings of RT studies, but it appears likely that this result depends upon certain aspects of the response conditions in their study.

The memory-capacity model. A popular notion about the span of apprehension is that it is just another manifestation of the "span of immediate memory" (e.g., Miller, 1956; Neisser, 1967; Sperling, 1953). The present data do suggest the role of a memory system in this task, but they challenge the notion that this memory operates like a storage bin with a fixed capacity. The multiple forms in a single display were found to be positively correlated with respect to the accuracy of their identification-i.e., the more items already in the memory, the more room was left for another item. This result seems to indicate the importance of organization factors in perceptual memory. An interesting coincidence is an increasing suspicion among verbal-memory researchers that verbal memory functions less like a storage bin than like a set of organizing programs (e.g., Bower, 1968; Neisser, 1967).

The correlation of multiple-form identifications. At least three alternative interpretations might account for the 
finding that the multiple identifications on a single trial are positively correlated in accuracy. The first interpretation attributes the interdependence of items to the $S$. The fact that the frequency distributions of correct identifications per trial were approximately normal, with greater variance than if the forms were independently identified, suggests that performance may be simply described by the mean and variance of a single underlying variable process. This process might be tentatively described as a variable "attentiveness." This is an intuitively reasonable interpretation, but it has no known support from other similar experiments (e.g., Eriksen \& Lappin, 1967; Lappin, 1967). Apparently, the correlation of multiple-form identifications derives from the use of many responses on each trial.

An alternative interpretation is that the variability in performance is attributable to the stimulus rather than to the $S$. An important feature of the displays that may affect S's performance might be patterns or relationships among the displayed forms. Despite the fact that the displays were constructed from approximately orthogonal combinations of forms, there were probably many trials on which $S$ could notice some pattern among the forms. Thus, the positive correlation between individual form identifications may be due to variability between displays with respect to the availability of some pattern description. This is a theoretically interesting possibility, in which the "items" processed are defined only in relation to other forms in the display. The present data do not provide for an adequate evaluation of this interpretation, but it is currently being tested in other experiments.

A third alternative might be that many of the errors in this task were order errors: $S$ might know many of the items in the display but be unable to recall their positions. An attempt was made to evaluate this hypothesis by tabulating the number of instances when the items in Positions $i$ and $i+1$ were reported in the reversed order. Such instances were surprisingly few-e.g., in the four-dimension condition, there were never more than three reversals for a total of 128 trials. Furthermore, if the limited span of apprehension were due to problems in keeping track of position information, then the task should become more difficult with increasing display sizes, but display size had only a very small effect on either the mean or variance of the correct responses per trial. There seems to be little interference among the displayed forms in this memory system.

Together, these considerations point to the importance of organizational properties of immediate visual memory. Contemporary research on visual-information processing does not yet provide adequate understanding of either the organization or limitation of the acquisition of information from brief visual displays. Quite aside from this problem, though, there is both methodological and theoretical significance to the evidence that this task depends upon different processes from those indicated by most RT measures. Other lines of evidence also suggest that tachistoscopic form identification and RT are measures of different processes (e.g., Fehrer \& Biederman, 1962; Lappin, 1968)

\section{APPENDIX B}

The binomial model for correcting for guessing may be expressed as follows:

$$
\begin{gathered}
\mathrm{C}=\mathrm{G} \cdot \mathrm{S} \\
\mathrm{S}=\mathrm{G}^{-1} \cdot \mathrm{C}
\end{gathered}
$$

APPENDIX A

It was not practical to construct complete stimulus-response confusion matrices for the complex displays used in this study. Accordingly, the information transmitted was estimated by the sum of the lower bounds of the information transmitted for each separate binary dimension relevant to the response. That is,

$$
\text { Est. IT }=\sum_{\mathbf{i}}\left[1+\mathrm{P}_{\mathbf{i}} \log _{2} \mathrm{P}_{\mathbf{i}}+\left(1-\mathbf{P}_{\mathbf{i}}\right) \log _{2}\left(1-\mathbf{P}_{\mathrm{i}}\right)\right]
$$

where $P_{i}$ is the percentage correct identification of the $i^{\text {th }}$ binary dimension. The right-hand term, which is summed over each relevant dimension, may be shown to be a lower bound on the amount of information that could be transmitted, given that a proportion, $\mathbf{P}_{\mathfrak{i}}$, of the identifications was correct. The actual information transmitted would equal this lower bound when both of the stimulus alternatives and both of the response alternatives were equally likely. Deviations from this condition were probably slight, since both stimulus alternatives did in fact occur an equal number of times. Assuming the displayed information to be equal to the number of relevant binary dimensions, the summation of the above terms would also provide a lower bound on the total information transmitted by the complete report. The underestimation of the above formula is increased by the assumption that the identifications of each dimension were independently correct; Table 3 shows that this assumption is not valid, and therefore, the formula slightly overestimates the uncertainty of the S's complete report. Consequently, the extent to which the equation underestimates the actual information transmitted increases with the amount of information displayed. where $C$ and $S$ are $(n+1) \times 1$ vectors giving the frequency with which $c$ and $s$ of the $n$ items are correctly identified and "seen," respectively, and $G$ is an $(n+1) \times(n+1)$ matrix whose entries represent the probability of correctly guessing $c-s$ of the items which were not seen. That is

$$
\begin{aligned}
& C=[f(c)] \\
& s=[f(s)] \\
& \mathbf{G}=\left[\begin{array}{ccccr}
b(n, 0, p) & 0 & \ldots & & 0 \\
b(n, 1, p) & b(n-1,0, p) & 0 & \ldots & 0 \\
\cdot & & & & \\
b(n, c, p) & \ldots & b(n-s, c-s, p) & \ldots & 0 \\
\cdot & & & & \\
p^{n} & p^{n-1} & \ldots &
\end{array}\right]
\end{aligned}
$$

where $b(n-s, c-s, p)$ is the bonomial density,

$$
f(c-s)=\left(\begin{array}{c}
n-s \\
c-s
\end{array}\right) p^{c-s}(1-s)^{n-c}
$$

and $p$ is the probability of guessing correctly. The inverse of the matrix $G, G^{-1}$, is easily obtained from $G$. 


\section{REFERENCES}

BOWER, G. H. Organization and memory. Address given at the meeting of the American Psychological Association, San Francisco, September 1968.

ERIKSEN, C. W., \& LAPPIN, J. S. Independence in the perception of simultaneously presented forms at brief durations. Journal of Experimental Psychology, 1967, 73, 468-472.

FEHRER, E., \& BIEDERMAN, I. A comparison of reaction and verbal report in the detection of masked stimuli. Journal of Experimental Psychology, 1962, 64, 126-130.

GLANZER, M., \& FLEISHMAN, J. The effect of encoding training on perceptual recall. Perception \& Psychophysics, 1967, 2, 561-564.

HABER, R. N. Effects of coding strategy on perceptual memory. Journal of Experimental Psychology, 1964, 68, 357-362.

HYMAN, R. Stimulus information as a determinant of reaction time. Journal of Experimental Psychology, 1953, 45, 186-196.

HYMAN, L. M., \& KAUFMAN, H. Information and memory span. Perception \& Psychophysics, 1966, 1, 235-237.

LAPPIN, J. S. Attention in the identification of stimuli in complex visual displays. Joumal of Experimental Psychology, 1967, 75, 321-328.

LAPPIN, J. S. Reaction time as a measure of visual processes. Paper presented at the meeting of the American Psychological Association, San Francisco, September 1968.

MACKWORTH, J. F. The relation between the visual image and post-perceptual immediate memory. Journal of Verbal Learning \& Verbal Behavior, 1963, 2, 75-85.

MILLER, G. A. The magical number seven, plus or minus two: Some limits on our capacity for processing information. Psychological Review, 1956, 63, 81-97.

NEISSER, U. Cognitive psychology. New York: Appleton-Century-Crofts, 1967

NEISSER, U. Decision-time without reaction-time: Experiments in visual scanning. American Joumal of Psychology, 1963, 76, 376-385.

POLLACK, I. Assimilation of sequentially encoded information. American Journal of Psychology, 1953, 66, 421-435.

SMITH, E. E. Choice reaction time: An analysis of the major theoretical positions. Psychological Bulletin, 1968, 69, 77-110.

SPERLING, G. The information available in brief visual presentations. Psychological Monographs, 1960, 74(11, Whole No. 498).

STERNBERG, $S$. Two operations in character recognition: Some evidence from reaction-time experiments. Perception \& Psychophysics, 1967, 2, 45-53.

WOODWORTH, R. S., \& SCHLOSBERG, $H$. Experimental psychology. (Rev. ed.) New York: Holt, Rinehart \& Winston, 1954

\section{NOTES}

1. This investigation was supported by Public Health Service Grant MH07722. A paper based on this research was presented at the convention of the Psychonomic Society, October 1967. The authors are grateful for the suggestions and criticisms of Robert Fox on earlier drafts of the paper.

2. Address: Department of Psychology, Vanderbilt University, Nashville, Tennessee 37203.

3. The initial intention was to measure the correlation in identification between all pairs of items by means of the chi-squared contingency coefficient. However, this plan was found to be unsatisfactory for two reasons: (a) The number of correct identifications differed widely between forms. Consequently, the contingency coefficients could not be directly compared between various pairs of items, due to this statistic having been drawn from quite different sampling distributions. (b) Approximately $90 \%$ of these correlations were position, with small negative values appearing unsystematically, indicating that this structure might be more simply described by the method of Table 3 and by the frequency distributions of correct responses per trial.

4. These are averaged percentages, over two sessions for each of four Ss, with widely varying numbers of cases for each observation. For $S 3$, there were several conditions in which there were no trials on which five additional forms were correctly identified, and the average is only over three $S s$ in those conditions.

(Accepted for publication May 14, 1969.) 